\title{
Atmospheric reactions of gaseous mercury with ozone and hydroxyl radical: Kinetics and product studies P. Biswajit and A.A. Parisa
}

\begin{abstract}
.
The dominant form of mercury in the atmosphere is $\mathrm{Hg}^{0}$. The oxidation processes are of great importance since oxidized mercury undergoes deposition and can become subject to bio- accumulation. Experimental data on the gaseous reactions of elemental mercury are very limited with compare to the reactions of $\mathrm{Hg}^{0}$ in solutions. We herein carried out kinetic and product studies on the reactions of gaseous $\mathrm{Hg}^{0}$ with $\mathrm{O}_{3}$ and hydroxyl radical (HO) under near atmospheric pressure $\left(750 \pm 1\right.$ Torr) and room temperature $(298 \pm 1 \mathrm{~K})$ in air and $\mathrm{N}_{2}$. $\mathrm{O}_{3}$ was produced in a silent discharge generator (OL 100/SB). Hydroxyl radicals were produced from the photolysis of isopropyl nitrite in the presence of NO. Kinetics of the reactions with $\mathrm{O}_{3} / \mathrm{HO}$ was studied using absolute and relative techniques by gas chromatography with mass spectroscopic detection (GCMS). The gas phase reaction between elemental $\mathrm{Hg}^{0}$ with $\mathrm{O}_{3}$, has been studied in different surface- to-volume (sly) ratios, and evidence for heterogeneous reactions was observed. Existence of mercuric oxide, $\mathrm{HgO}$ by the reaction of atomic $\mathrm{Hg}^{0}$ with $\mathrm{O}_{3}$ has been determined in the gas phase from the suspended aerosols using high temperature mass spectrometry.
\end{abstract}

\section{INTRODUCTION}

One of the most toxic elements, $\mathrm{Hg}$ is released into the lower atmosphere from a variety of natural and anthropogenic sources [1]. Rapid depletion of $\mathrm{Hg}^{0}$ has been observed from the atmospheric boundary during spring in the high-Arctic region [2], Arctic [3], sub-Arctic [4] and is associated with surface snow and ice [5]. The concentration of atmospheric $\mathrm{Hg}^{0}$ which is mainly in the elemental mercury in the range of 1 to $4 \mathrm{ngm}^{-3}[6] \mathrm{and}^{-}$ play a important role in the atmospheric chemistry of the heavy metal. The average lifetime of elemental $\mathrm{Hg}^{0}$ is estimated to be from 0.5 to 2 years [7]. Due to some atmospheric oxidants, elemental mercury is transferred into the oxidized state, e.g., as in its methylated form, thereby spreads into the ecosystem and becomes subject to bioaccumulation [8]. The evidence for oxidation of elemental mercury by $\mathrm{O}_{3}$ in the aqueous phase due to high $\mathrm{O}_{3}$ concentration in the stratosphere has been suggested $[9,10]$. It is important to evaluate the direct impact of $\mathrm{O}_{3}$ initiated oxidation reaction of mercury on human health and the chemistry of the global atmosphere. The major daytime oxidant is HO radical, the most important reactive species in the troposphere and a key player for initiating oxidation of trace compounds in the atmosphere [11]. The studies of gaseous reactions of elemental mercury with $\mathrm{HO}$ radicals are very limited in contrast to the reactions of $\mathrm{Hg}^{0}$ in solution. An attempt has therefore been made to study the chemistry of mercury with $\mathrm{HO}$ and ozone in connection with mercury depletion events observed in several locations 'in the high-Arctic, -Antarctic, and sub-Arctic. Our present study has been carried out for understanding the kinetics and product of gas phase reactions of $\mathrm{Hg}$ with $\mathrm{O}_{3}$ and $\mathrm{HO}$ under near atmospheric condition using absolute and relative rate techniques by gas chromatography with mass spectroscopic detection.

\section{EXPERIMENTAL}

The kinetic investigations of the reactions of gaseous $\mathrm{Hg}^{0}$ with $\mathrm{O}_{3}$ and hydroxyl radical (HO) were performed under near atmospheric pressure (750 \pm 1 Torr) and room temperature $(298 \pm 1 \mathrm{~K})$ in air and $\mathrm{N}_{2}$ using absolute and relative techniques by gas chromatography with mass spectroscopic detection (GCMS).Mercury and reference concentrations were monitored by MS ( quadrupole MSD HP5973) after a separation on gas chromatograph equipped with $0.25 \mathrm{~mm}$ ID x $30 \mathrm{~m}$ crossed linked phenyl-methylsiloxane column using SIM mode.

The absolute reaction rate of the reaction of mercury with $\mathrm{O}_{3}$ were studied under pseudo-firstorder conditions with respect to $\mathrm{Hg}^{0}$. To perform kinetic studies of the reaction of $\mathrm{Hg}^{0}$ with $\mathrm{HO}$, we used relative rate technique:

$$
\begin{array}{lr}
\mathrm{HO}^{\circ}+\mathrm{Hg}^{0} \rightarrow \text { Products } & k_{H g} \\
\mathrm{HO}^{\circ}+\text { Reference } \rightarrow \text { Products } & k_{\text {Ref }}
\end{array}
$$

The ratio of the rate constants $\mathrm{kHg} / \mathrm{k}_{\mathrm{Ref}}$ was determined from the following equation:

$$
\ln \left\{\frac{[H g]_{0}}{[H g]_{t}}\right\}=\frac{k_{H g}}{k_{R e f}} \ln \left\{\frac{[R e f]_{0}}{[R e f]_{t}}\right\}
$$

where $[\mathrm{Hg}]_{0}$ and $[\mathrm{Ref}]_{0}$ are the initial concentrations, and $[\mathrm{Hg}]_{t} \mathrm{t}$ and $[\mathrm{Ref}]_{t}$ are the concentration at time t. A plot of $\ln \left\{\frac{[\mathrm{Hg}]_{0}}{[\mathrm{Hg}]_{t}}\right\}$ vs $\ln \left\{\frac{[R e f]_{0}}{[R e f]_{t}}\right\}$ should give a straight line with a zero intercept, if 
the extend of secondary reactions are negligible.

Experiments were carried out in double-walled 2- and 3- L Pyrex flasks. Temperature was regulated to $\pm 1{ }^{\circ} \mathrm{C}$ by circulating water through the outer jacket, using a circulator (Neslab RTE 111). In order to avoid wall losses, the flask inside was treated by Halocarbon Wax (SUPELCO) as described by in our group's publication previously [ 12]. A vacuum system was u sed to prepare the gaseous reactants. $\mathrm{O}_{3}$ was produced in a silent discharge generator (OL 100/SB). An ultraviolet-visible spectrophotometer (UV-VIS, Varian Cary-50 Bio) was used to monitor the ozone concentration. HO radicals were produced by photolysis $(300<\lambda<400 \mathrm{rim})$ employing isopropyl nitrite in presence of NO which enhances the formation of HO radical and reduces the ozone formation. Synthetic air was used as batch gas. Isopropyl nitrite was prepared by the action of nitrous acid and isopropyl alcohol at $0^{\circ} \mathrm{C}$. Purity was checked with GC-MS and stored at $0^{\circ} \mathrm{C}$ in the dark.

\section{RESULTS AND DISCUSSION}

It has been mentioned in the literature that the reaction of mercury with $\mathrm{O}_{3}$ can be catalyzed by surfaces [6]. To minimize this effect, the reaction cell was coated with halocarbon wax for kinetic experiments. The reaction of $\mathrm{Hg}$ with $\mathrm{O}_{3}$ may precede [6] either according to equations (4) or (5), where reaction (4) is simple bimolecular gas phase reaction and reaction (5) has a complex nature.

$$
\begin{aligned}
& \mathrm{Hg}^{0}(\mathrm{~g})+\mathrm{O}_{3}(g) \Rightarrow \mathrm{HgO}(\mathrm{g})+\mathrm{O}_{2}(g) \quad \Delta G_{298}^{0}=-171 \mathrm{kJmole} \mathrm{J}^{-1} \\
& \mathrm{Hg}^{0}(g)+\mathrm{O}_{3}(g) \Rightarrow \mathrm{HgO}(s)+\mathrm{O}_{2}(g) \quad \Delta G_{298}^{0}=-254 \mathrm{kJmole}^{-1}
\end{aligned}
$$

The large negative Gibbs free energy indicates the near complete conversion of $\mathrm{Hg}^{0}$ to $\mathrm{HgO}$. Existence of mercuric oxide, $\mathrm{HgO}$ has been determined in the gas phase from the suspended aerosols, and on the wall of the reaction chambers using high temperature mass spectrometry according to the method. Products were collected by a flow of gas from a reaction chamber through a $1.1 \mathrm{~mm}$ ID x $10 \mathrm{~cm}$ length Pyrex liquid $\mathrm{N}_{2}$ cooled trap. Condensed products were evaporated at step-wise elevated temperature from the tube to a chemical ionization ion source using direct probe technique. An example of a pseudo-firstorder plot, depicted in Figure 1, of the reaction of $\mathrm{Hg}^{0}$ with $\mathrm{O}_{3}$ suggested that both a gas phase reaction and a heterogeneous gas-solid reaction occurring simultaneously and there is a significant increase in the

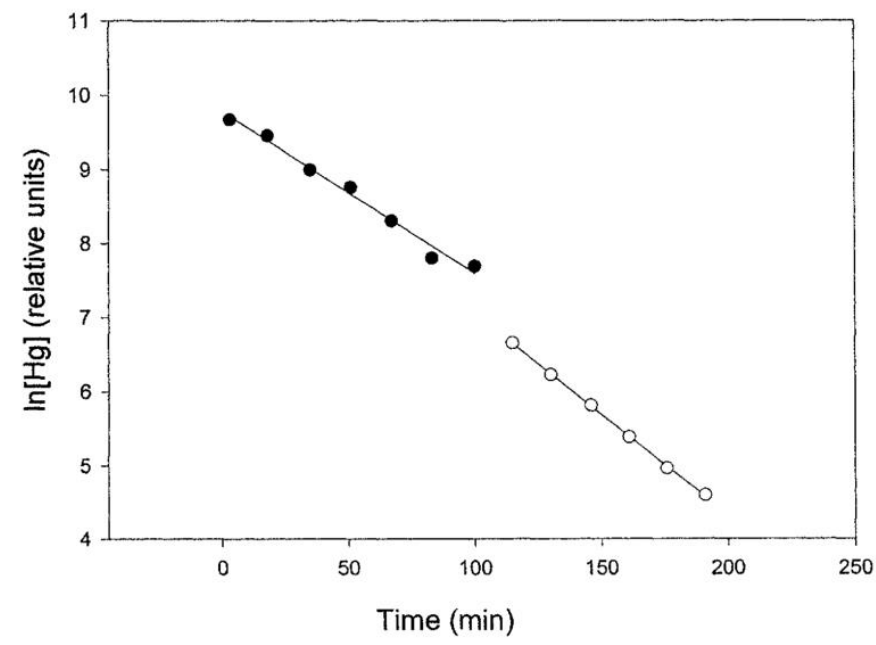

Figure 1. Typical pseudo-first-order plot for the reaction of $\mathrm{Hg}^{0}$ with $\mathrm{O}_{3}$ at $298 \mathrm{~K}$. Wall treated with halocarbon wax.

rate constant with increasing $\mathrm{s} / \mathrm{v}$ ratio.

HO- initiated reactions of $\mathrm{Hg}^{0}$ were studied by relative rate technique using cyclohexane and n-butane as the Reference molecule. The mechanism of the HO-initiated reaction of $\mathrm{Hg}^{0}$ has been suggested [13] that there is a initial formation of $\mathrm{HgOH}$, which is slightly exothermal $\sim 6 \mathrm{kJmole}^{-1}$. $\mathrm{HgOH}$ finally scavenged by $\mathrm{O}_{2}$ in an ambient air according to the equation (7). 
https://jp4.journaldephysique.org/articles/jp4/abs/2003/05/jp4pr5p189/jp4pr5p189.html

$$
\begin{gathered}
\mathrm{Hg}^{0}+\mathrm{HO}^{\cdot} \rightarrow \cdot \mathrm{HgOH} \\
\mathrm{HgOH}+\mathrm{O}_{2} \rightarrow \mathrm{HgO}+\mathrm{HO}_{2}
\end{gathered}
$$

Good linearity of relative rate plots was obtained for both references of cyclohexane and n-butane. Both ozone and HO initiated reactions seem to be kinetically too slow to account for ozone depletion observed in the poles during the sunrise.

\section{Acknowledgements}

We cordially thank the Natural Science and Engineering Research Council of Canada (NSERC), the Fond pour la Formation de Chercheurs et l'Aide a la Recherche (FCAR), the Canadian Foundation for Innovation (CFI), the COMERN project, and Environment Canada for financial support.

\section{References}

[1] Lindqvist 0. and Rodhe H., Tellers 37B (1985) 136.

[2] Schroeder W. H., Anlauf K. G., Barrie L. A., Lu J. Y., Steffen A., Schneeberger D. R. and Berg T., Nature 394 (1998) 331-332.

[3] Lindberg S. E., Brooks S., Lin C. J., Scott K. J., Landis M. S., Stevens R. K., Goodsite M. and

Richter A., Environ. Sci. Tech. 36 (2002) 1245-1256.

[4] Poissant L., personal communication 2001.

[5] Lu J. Y.,Schroeder W. H., Barrie L. A., Steffen A., Welch H. E., Martin K., Lockhart L., Hunt R.

V., Boila G. and Richter A., Geophys. Res. Lett. 28 (2001) 3219-3222. [6]Hal1 B., Water, Air, and Soil Pollution 80 (1995) 301-315.

[7] Seiler W., Eberling C. and Slemr F., Pageoph 118 (1980) 963-973.

[8] Gardfeldt K., Sommar J., Stromberg D. and Feng X., Atmos. Environ. 35 (2001) 3039-3047.

(9] Iverfeldt A. and Lindqvist 0., Atmos. Environ. 20 (1986) 1567-1573.

[10] Munthe J., Atmos. Environ. 26A (1992) 1461-1468.

[11] Niki H., Maker P. S., Savage C. M. and Breitenbach L. P., J. Phys. Chem. 87 (1983) 4978-4981.

[12] Ariya P. A., Khalizov A. and Gidas A., J. Phys. Chem. A 106 (2002) 7310-7320, 2002.

[13] Stromberg D., Ph.D. thesis, Goteborg University and Chalmrs University of Technology 1990. 